\title{
Mutation analysis of TP53 in colorectal cancer, Peshawar, Khyber Pakhtunkhwa, Pakistan
}

Ihsan Ali ${ }^{2 a}$, Aamna Fayyaz ${ }^{3 a}$, Zahid Anwar ${ }^{4}$, Irfan Saif ${ }^{1}$, Ikram Khan', Muhammad Jahangir ${ }^{5}$, Mian Adnan Kakakhel $^{1,3^{*}}$

${ }^{1}$ MOE Key Laboratory of Cell Activities and Stress Adaptations, School of Life Sciences, Lanzhou University, Lanzhou, China

${ }^{2}$ College of Life Science, Northwest University, Xi'an, Shaanxi province, China

${ }^{3}$ Department of Zoology, Kohat University of Science and Technology, Kohat, Khyber Pakhtunkhwa, Pakistan

${ }^{4}$ Animal Sciences Institute, Faculty of Animal Genomics and Biotechnology, PARC Institute of Advanced

Studies in Agriculture, National Agricultural Research Center, Islamabad, Pakistan

${ }^{5}$ National Clinical Research Center for Mental Disorders, Xiangya School of Medicine, Central South University, Changsha, Hunan, China

Received: 2021-01-27.

Accepted: 2021-02-19

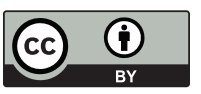

This work is licensed under a Creative Commons Attribution 4.0 International License

\section{J Clin Med Kaz 2021; 18(2):25-30}

Corresponding author:

Mian Adnan Kakakhel.

E-mail: zoology863@gmail.com;

ORCID: https://orcid.org/0000-0002-8069-1563

${ }^{\text {a }}$ Co-first author contributed equally

\begin{abstract}
Aim: Colorectal cancer is a kind of solid tumor and third most common of cancer which leads to death. It is a heterogeneous disease characterized by genetic and epigenetic aberrations. The present study was aimed to reveal the mutation at TP53 in Peshawar Pakistan.

Material and methods: For this purpose, a total of 50 blood samples in EDTA tubes was collected from Peshawar with complete information of patients using questionnaire. The polymerase chain reaction was performed.

Results: The results of the present study have revealed that the ratio of colorectal cancer in males is higher $62 \%$ than females (38\%). Histopathological results have indicated that moderately differentiated adenocarcinoma is 25 (50\%) followed by poorly differentiated adenocarcinoma 15 (30\%), Well-differentiated adenocarcinoma 8 (16\%), and Metastatic adenocarcinoma $2(4 \%)$ in 50 colorectal cancer patients. The nucleotide sequence of the human TP53 gene of colorectal cancer patients was aligned with the human wild-type TP53 database sequence with NC_191170 (NCBI) using CLUSTALW. After BLASTING, the mutation was found in exon 5 and exon 7 of TP53, while no mutation was found in exon 8 of TP53. That patient in which point mutation was found in exon 5 and 7 respectively showed less survival as compared to that of colorectal cancer patients having no point mutation in the TP53 gene.

Conclusion: The present study concluded that point mutations were found in exons 5\&7 of the TP53 gene and patients having TP53 gene mutations shown less survival rate compared to colorectal cancer patients having no mutations.
\end{abstract}

Key words: colorectal cancer, mutation, TP53 gene, PCR, blasting

\section{Introduction}

Nowadays, cancer is one of the leading disease in human population that can spread among all living cells with the ability to segregate [1], and uncontrollable and unchecked division [2]. Among all types of cancer, colorectal cancer (CRC) is one of very common type of cancer in all over the world. There are approximately 500,000 per year of CRC cases. Among all type of cancer, $\mathrm{CRC}$ is third most common type [3]. Colorectal cancer is the second most common cancer and leading cause of death worldwide [4], and 5th leading cancer type in P. R. China [5]. The TP53 gene is mutated in all most $50 \%$ of all types of cancer regarding human [6]. Human TP53 gene residing on chromosome $17 \mathrm{p}$, comprising of 10 introns and 11 exons [7]. Normal p53 of 393 amino acids, with several functional domains including Transactivation domain, proline rich domain, Basic and tetramerization domain. In normal cells, p53 is tightly regulated at very low basal level. MDM2 (murine/human double minute 2), inhibits p53 transcriptional activity by binding to its transactivation domain and as well functioning as E3 ubiquitin ligase resulting in to p53 ubiquitination $[8,9]$. The highest risk of CRC occurrence is mainly linked to certain factors that leads to CRC i.e., high intake of preserved eatables, smoking, alcohol abuse, and inflammatory bowel disease [10].

Pakistan, like many other South Asian countries, have been placed in low-risk zone CRC. Though, a latest 
study have reported in CRC cases for patients above the age of 50 years [11]. From global perspective, Pakistan falls into a highrisk region for colorectal cancer. According to the collective cancer registry from 1994 up to 2014 published by Shaukat Khanum Memorial hospital Lahore (SKMH), CRC is ranked third in number (4.4\% in males and $2.8 \%$ in females) among top 10 malignancies in both sexes of Pakistan's population [12]. CRC have been appeared as uncommon type of cancer in Pakistan that have effected 5.9\% men and 5.0\% women [13]. The risk factor such as, smoking and high intake preserved food are being expensively extended in Pakistan. Hence, there is a chance of rapid rise of CRC in Pakistan in coming few decades [14].

The frequency of $\mathrm{CRC}$ is $22.8 \%$ per 100,000 people aged between 40 and 49 and $6.8 \%$ in 30 t 39 years [15]. The comparative risk of emerging CRC is lower in those people who have more physical activities as compared to that who are not involve in physical activities [16]. In colorectal cancer patients, the liver is the most primary site for metastasis $(93.1 \%)$, followed by lungs, and lymph nodes [17]. Rectum (51.3\%), sigmoid $(14.2 \%)$, and descending colon $(4.7 \%)$ are the most common sites for CRC [18]. Many technologies have now been emerged to treat cancer and types of cancer e.g., [1] have used the ethanolic extract of Allacanthos crab against cancer cells and concluded that this extract might be potential source of curing cancer cells. Nanotechnology is one of the important and emerging field of science that act as drug delivery, medicine, and anti-cancer agent [15]. The nanoparticles are small nanosized materials 1-100 $\mathrm{nm}$ in size [19], that might act as potential source for cancer cells [20].

Peshawar is the capital of Khyber Pakhtunkhwa. Most of the CRC patients come to Peshawar for their treatment. Therefore, we conducted our study with objective that TP53 is a significant tumor suppressor, which is mutated in further stages of many cancers and leads to resistance to chemotherapy. The current study was aimed to conduct to reveal mutations of TP53 in colorectal cancer in Peshawar, Khyber Pakhtunkhwa, Pakistan.

\section{Material and methods Ethical approval}

The present study was ethically approved by the committee of "Department of Zoology, Kohat University of Science and Technology, Kohat 26000, Khyber Pakhtunkhwa, Pakistan”.

\section{Study area}

Peshawar is the capital city of Khyber Pakhtunkhwa. It is a very congested city in the whole province. The population of Peshawar is 1.7 million (2017). Peshawar lies between $33^{\circ} 44^{\prime}$, $34^{\circ} 15^{\prime}$ north latitude, $71^{\circ} 22^{\prime}$, and $71^{\circ} 42^{\prime}$ east longitude [21].

\section{Study population}

CRC patients from five major hospitals, Institute of Radiotherapy and nuclear medicine (IRNUM), Lady Reading Hospital (LRH), Khyber Teaching Hospital (KTH), Hayatabad Medical Complex (HMC), North West General Hospital of Peshawar were selected, to carry out the present study.

\section{Sample collection}

Total 50 blood samples were obtained from CRC diagnosed patients aseptically in ETDA tubes, along with complete information of the patients: age, gender, the onset of first symptoms, dietary habits, treatment, tumor location, time of first surgery, patients follow up and staging \& grading were obtained on "patient info. Sheet".

\section{DNA extraction}

Genomic DNA (YeaStar Genomic DNA Kit) was used to extract from blood plasma by taking $250 \mu \mathrm{l}$ of blood in Eppendorf tube and $750 \mu \mathrm{l}$ of solution A were mixed by inverting the tubes 4-6 times and kept at room temperature for analysis.

\section{TP53 amplification}

Three oligonucleotide primer pairs (Table 1) were designed for TP53 to amplify fragments of 193, 202 and $158 \mathrm{bp}$ corresponding to exons 5, 7 and 8 of the human TP53 gene. DNA concentration, cycling time and other amplification conditions were optimized for each primer pair on blood DNA.

\section{Table 1}

Sequences of primers used for amplification of exons 5, 7 and 8 of TP53 gene [TP53 gene ID: 7157]

Sequence of Primer Length of PCR product

EXON 5 F: GTACTCCCCTGCCCTCAACA $193 \mathrm{bp}$ R: CTGCTCACCATCGCTATCTG

EXON 7 F: GGCTCTGACTGTACCACCAT $202 \mathrm{bp}$ R: GGAAGAAATCGGTAAGAGG

EXON 8 F: GGTAATCTACTGGGACGGAAC $158 \mathrm{bp}$ R: GCTTCTTGTCCTGCTTGCTT

\section{PCR master mixture conditions for TP53 Gene}

The fragments were amplified in $25-\mu 1$ reaction volume containing $1-\mu \mathrm{l}$ of genomic DNA; $2.5 \mu \mathrm{l}$ of each primer; $2.5 \mu \mathrm{l}$ dNTP-Mix; $2.5 \mu 1$ of buffer $10 \mathrm{X} ; 0.4 \mu \mathrm{l}$ of Taq-polymerase and $13.6 \mu \mathrm{l}$ of distal water. The data is given in Table 2 .

\section{Table 2 PCR master mixture conditions for TP53}

\begin{tabular}{lll} 
PCR - Master Mix & $25 \mu \mathrm{l} \mathrm{Vol.}$ & Primers Pairs \\
\hline DNA & $1 \mu \mathrm{l}$ & Tp53 -Exon 5 \\
F' Primer (1:100) & $2.5 \mu \mathrm{l}$ & Tp53 -Exon 7 \\
R' Primer (1:100) & $2.5 \mu \mathrm{l}$ & \\
dNTP -Mix (2.5mM) & $2.5 \mu \mathrm{l}$ & Tp53- Exon 8 \\
Buffer (10X) & $2.5 \mu \mathrm{l}$ & \\
Taq-polymerase (1U) & $0.4 \mu \mathrm{l}$ & \\
dist H20 & $13.6 \mu \mathrm{l}$ & \\
\hline
\end{tabular}

\section{PCR conditions for Exon 5\&7 TP53}

PCR was performed in the Master cycler (Eppendorf) machine under the following conditions; initial denaturation was performed at $94 \circ \mathrm{C}$ for $5 \mathrm{~min}$, which was then followed by 35 cycles each at $94{ }^{\circ} \mathrm{C}$ for 30 second; annealing at $58{ }^{\circ} \mathrm{C}$ for 30 $\mathrm{sec}$ and initial extension at $72{ }^{\circ} \mathrm{C}$ for $30 \mathrm{sec}$ and then there was a final extension at $72 \circ \mathrm{C}$ for $5 \mathrm{~min}$ and then the end temperature was set at $4 \circ \mathrm{C}$.

\section{PCR conditions for exon 8 TP53}

PCR was performed in the Master cycler (Eppendorf) machine under the following conditions; initial denaturation was performed at $94{ }^{\circ} \mathrm{C}$ for $5 \mathrm{~min}$, which was then followed by 35 cycles each at $94{ }^{\circ} \mathrm{C}$ for 30 second; annealing at $57{ }^{\circ} \mathrm{C}$ for 30 $\mathrm{sec}$ and initial extension at $72 \circ \mathrm{C}$ for $30 \mathrm{sec}$ and then there was a final extension at $72{ }^{\circ} \mathrm{C}$ for $5 \mathrm{~min}$ and then the end temperature was set at $4 \circ \mathrm{C}$. 


\section{Impact of TP53 mutations on the prognosis of CRC patients}

To find out the impact of mutations in the TP53 gene on colorectal patient survival rate PCR product were sequenced.

\section{TP53 Sequencing}

PCR products were run on $1.5 \%$ agarose gel \& recovered the amplified product with thermos Scientific Genomic DNA Purification Kit. The recovered DNA was quantified a ratio of the 260/280nm spectrophotometer. To find mutations in TP53 gene, DNA was sent Agha Khan University, Karachi [ $3 \mu 1$ PCR product $+27 \mu 1$ water $=30 \mu 1]$.

\section{Results}

\section{Demography of the Study}

The present study was based on 50 colorectal cancer diagnosed patient of age (16-74 years) were comprises of 31 males $(62 \%)$ and 19 females (38\%), from different areas of District Peshawar. The demographic information of the participants is presented in Table 3. The patients were divided into different age groups with different percentages, patients between age group of 16-20 years were $2(4 \%)$, patients in age groups $21-25$ years were $4(8 \%)$, those in between age group of 26-30 years were 7 (14\%), likewise in age group 31-35 years had $5(10 \%)$ patients, while age groups $36-40$ years $2(4 \%)$, $41-45$ years $3(6 \%), 46-50$ years $8(16 \%) 51-55$ years $6(12), 56-$ 60 years $6(12 \%), 61-65$ years $5(10 \%), 66-70$ years $1(2 \%), 71-$ 75 years $1(2 \%)$ had patients respectively.

\begin{tabular}{lll}
\multicolumn{1}{r}{ Table 3} & $\begin{array}{l}\text { Socio- demographic characteristics of } \\
\text { participants / patients }\end{array}$ \\
Sex & Number of Patients & Percentage (\%) \\
\hline Male & 31 & 62 \\
Female & 19 & 38 \\
Age group & & \\
$16-20$ & 2 & 4 \\
$21-25$ & 4 & 8 \\
$26-30$ & 7 & 14 \\
$31-35$ & 5 & 10 \\
$36-40$ & 2 & 4 \\
$41-45$ & 3 & 6 \\
$46-50$ & 8 & 16 \\
$51-55$ & 6 & 12 \\
$56-60$ & 6 & 12 \\
$61-65$ & 5 & 10 \\
$66-70$ & 1 & 2 \\
$71-75$ & 1 & 2 \\
\hline
\end{tabular}

\section{Histopathology of colorectal cancer}

In our study we found patients with high rate of moderately differentiated adenocarcinoma that is $25(50 \%)$, secondly followed by poorly differentiated adenocarcinoma which is 15 $(30 \%)$, while Well differentiated adenocarcinoma is $8(16 \%)$ and Metastatic adenocarcinoma is $2(4 \%)$ in $50 \mathrm{CRC}$ patients as given below in Figure 1.

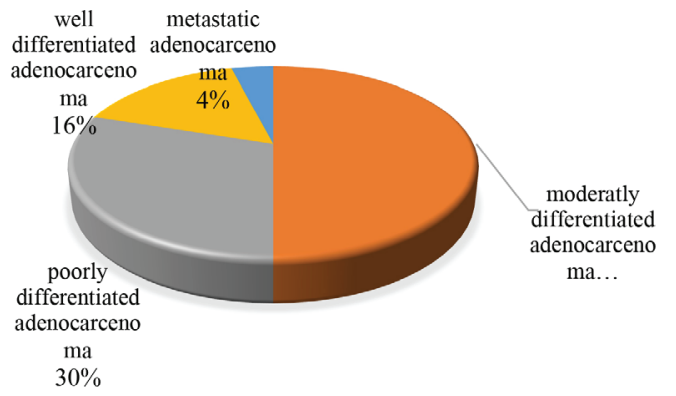

Figure 1. Histopathology of colorectal cancer patients based on differentiated adenocarcinoma.

Journal of Clinical Medicine of Kazakhstan: 2021 Volume 18, Issue 2

\section{CRC patients' distribution on basis of grading}

We distributed 50 patients on basis of grading i.e. differentiation of cancerous cells from normal cells according to which $34 \%$ patients were having a high grade of carcinoma while $66 \%$ were having low-grade carcinoma as mentioned in Figure 2.

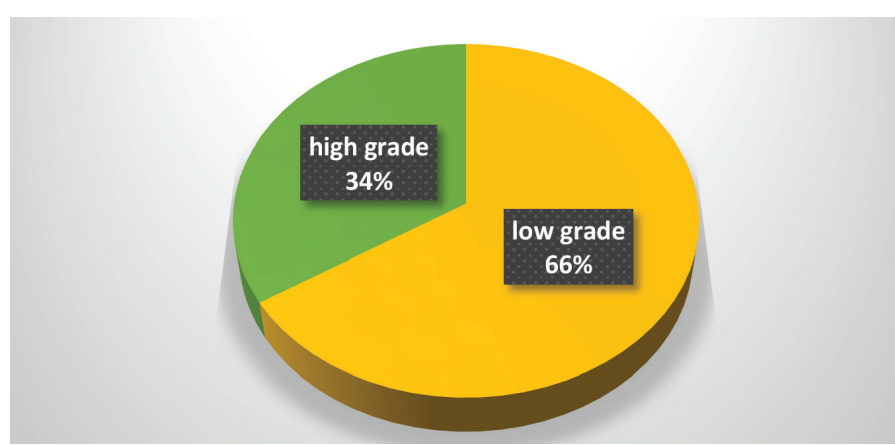

Figure 2. Distribution of CRC patients based on tumor grading (High grade ad low grade)

\section{Grouping of CRC patients on basis of staging}

In our study, we found patients of CRC belong to four stages of cancer but with a different percentage. Patients of stage I was $6 \%, 22 \%$ were of stage II while Stage III and Stage IV were $36 \%$ respectively given below in Figure 3.

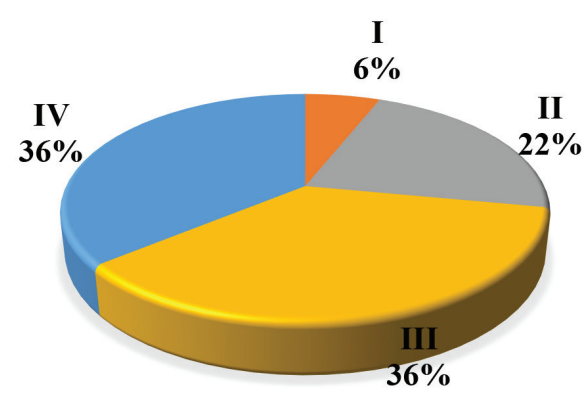

Figure 3. Division and distribution of CRC patients based on different stages of cancer

\section{Presence of tumor in a different location}

CRC patients have a different location of the tumor from one another on the colon and rectum part of large intestine. Tumors were not present on the same location in all the patients instead they were on different positions and sites. The site that comprises the highest number of the tumor was rectum in $50 \%$ patient, the second is a colon in $22 \%$ patient and $10 \%$ were on rectosigmoid. Colon-sigmoid, sigmoid, and cecum had $4 \%$ of tumors respectively while rectum and liver marts, ascending and $\mathrm{CRC}$ was of $2 \%$ each as shown in Figure 4.

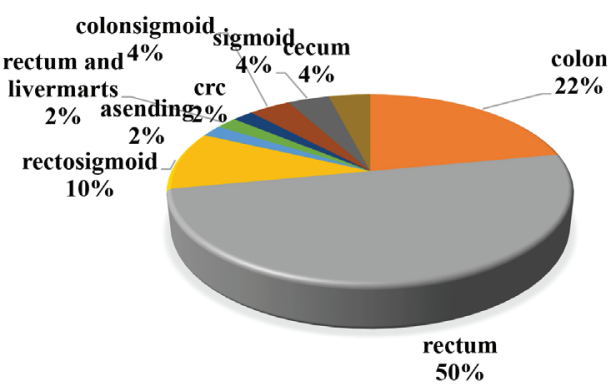

Figure 4. Presence of tumor based on the different location in the colon and rectum part of large intestine 


\section{Regime gave to $\mathrm{CRC}$ patients}

CRC patients of different cancer stages were treated differently; some were treated with chemotherapy while some were given radiation. Those, which were not operated yet were grouped in others. These include $84 \%$ were under chemotherapy, while $12 \%$ were given Radiation and only $4 \%$ were under other treatment as shown in Figure 5.

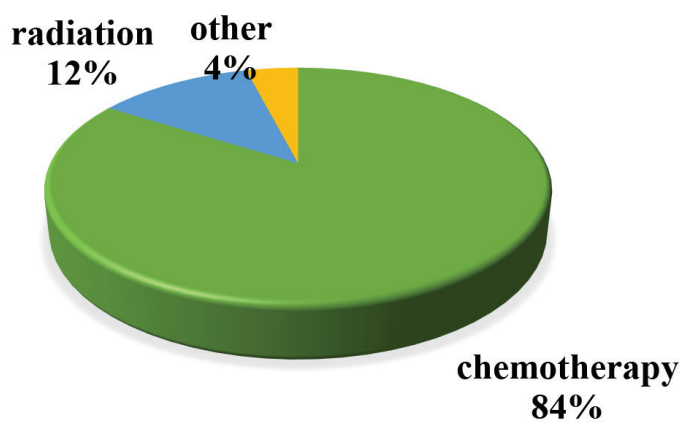

Figure 5. Regime of the cancer patients. Mostly treated based on chemotherapy followed by radiations

\section{PCR results of Exon-5 (TP53) run on 1.5\% gel electrophoresis}

Amplification of exon-5 of tumor suppressor protein 53, bands were obtained through polymerase chain reaction shown in Figure 6.

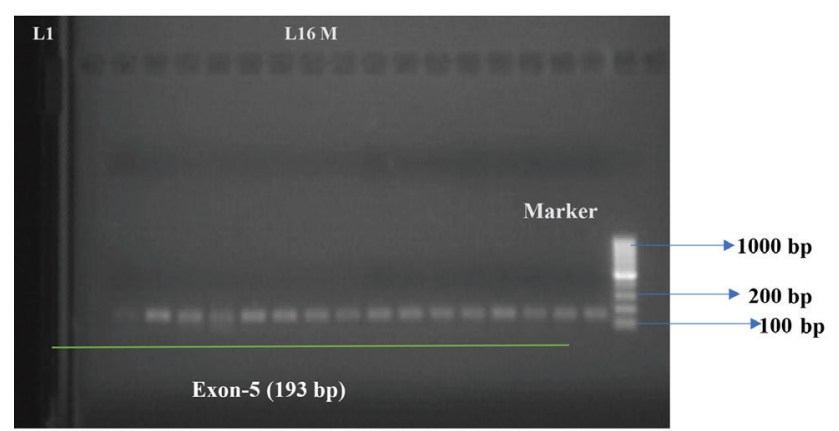

Figure 6. PCR results visualized by Agarose gel electrophoresis of Exon-5 (TP53) Agarose gel electrophoresis (1.5\%) results of exon 5 of the human TP53 gene. L7-L76: amplified bands (193bp) of exon 5, L17/M: DNA-marker (1000bp).

\section{PCR results of Exon-7 (TP53) run on $1.5 \%$ gel electrophoresis}

On amplification of exon-7 of TP 53, following bands of exon 7 were obtained through polymerase chain reaction shown in Figure 7.

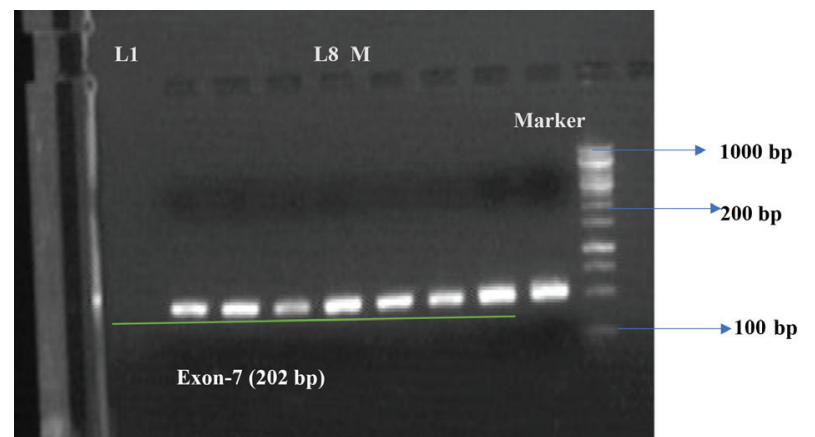

Figure 7. Agarose gel electrophoresis of PCR results of Exon-7 (TP53) Agarose gel electrophoresis (1.5\%) results of exon 7 of the human TP53 gene. L7-L8: amplified bands (202bp) of exon 7, L9/M: DNA-marker (1000bp).

\section{PCR results of Exon-8 (TP53) run on 1.5\% gel electrophoresis}

On amplification of exon- 8 of TP 53, following bands of exon 8 were obtained through polymerase chain reaction. The Figure 8 below shows the Exon-8 (TP53)

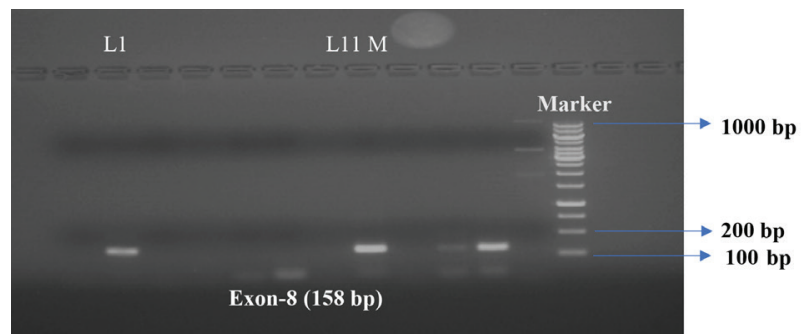

Figure 8. Agarose gel electrophoresis of PCR results of Exon-8 (TP53) Agarose gel electrophoresis (1.5\%) results of exon 8 of the human TP53 gene. L7,L7,L9,L10:amplified bands (158bp) of exon 8 , L12/M: DNA-marker (1000bp).

\section{TP53-mutation analysis}

The nucleotide sequence of the human TP53 gene of CRC patients was aligned with a human wild-type TP53 database sequence with NC_191170(NCBI) using CLUSTALW.

\section{TP53-mutations within Exons 5, 7 \& 8}

We sent DNA samples of 20 colorectal cancer patient to Agha Khan University Karachi for sequencing of TP53 gene. Sequencing results that we obtain were BLAST with wildtype sequence of TP53, available at NCBI. After BLASTING, we found mutations in exon 5 and exon 7 of TP53 while no mutation was found in exon 8 of TP53. Here is the summary of all mutation we found. We found 3-point mutations in exon 5 of TP53, these mutations were in Patient number 7, 20 and 28. Patient number 7 the point mutation was at bp 150 and Guanine was replaced by Adenine, when the impact on protein level was checked it was at amino acid 44 alanine was replaced by threonine. The point mutation in patient 20 was at bp 160 at this point cytosine replaces thymine and having impact at 48 amino acid and replaces threonine to Isoleucine, while the point mutation was seen at 169 bp in patient number 28; replacing Cytosine by Thymine and having impact on protein level at 58 amino acid places Alanine instead of Valine. A silent mutation is found at exon 7 of TP 53 in patient number 5 as given below in Table 4.

\section{Table 5} Impact of P53 mutations in exon 5 on survival

\begin{tabular}{ll} 
Exon-5 TP53-Exons & Mt-TP53 (Survival) \\
\hline T7 & $\downarrow$ (Compared to CRC patients having no mutations) \\
T20 & $\downarrow$ (Compared to CRC patients having no mutations) \\
T28 & $\downarrow$ (Compared to CRC patients having no mutations) \\
T5 & $\downarrow$ (Compared to CRC patients having no mutations)
\end{tabular}

\section{Table 6} Impact of P53 mutations in exon 5 on survival

Exon-5 TP53-Exons Mt-TP53 (Survival)

\begin{tabular}{ll}
\hline T7 & $\downarrow$ (Compared to CRC patients having no mutations) \\
T20 & $\downarrow$ (Compared to CRC patients having no mutations) \\
T28 & $\downarrow$ (Compared to CRC patients having no mutations)
\end{tabular}




\begin{tabular}{|c|c|c|c|c|c|c|}
\hline Exon \# & Patient \# & Wild type codon & Mutant codon & Mutation & Impact on DNA level & $\begin{array}{l}\text { Impact on protein } \\
\text { level }\end{array}$ \\
\hline \multirow[t]{3}{*}{5} & T7 (Female) & GCT(Ala) & ACT(Thr) & Point mutation & bp $150 \mathrm{G} \rightarrow \mathrm{A}$ & $\mathrm{Ala} \rightarrow \mathrm{Thr}$ \\
\hline & T20 (male) & ACC(Thr) & ATC(Ile) & Point mutation & bp $160 \mathrm{C} \rightarrow \mathrm{T}$ & Thr $\rightarrow$ Ils \\
\hline & T28 (male) & GCT(Ala) & GTT(Val) & Point mutation & bp $170 \mathrm{C} \rightarrow \mathrm{T}$ & $\mathrm{Ala} \rightarrow$ Val \\
\hline 7 & T5 (male) & GCA(Ala) & ACA(Thr) & Point mutation & bp $130 \mathrm{C} \rightarrow \mathrm{A}$ & $\mathrm{Ala} \rightarrow \mathrm{Thr}$ \\
\hline 8 & & & $\begin{array}{l}\text { Non-mutations } \\
\text { found }\end{array}$ & & & \\
\hline
\end{tabular}

\section{Impact of P53 mutations in exon 5 and 7 on patient's survival}

That patient in which point mutation was found on exon 5 and 7 respectively they showed less survival as compared to that of colorectal cancer patients having no point mutation in the TP53 gene. The data regarding P53 mutations in exon 5 and 7 is given below in Table 5 and 6 respectively.

\section{Discussion}

Colorectal cancer with many similar characteristics, is compact cancer that develop in various parts of the colon or rectum and commonly known as cancer of large bowel or intestine. CRC emerged as one of the most common cause of death among cancer-related deaths. Approximately, one million people each year develop colorectal cancer around the world. Most people with colorectal cancer die within the time period of five years from the day of first diagnosis [22]. According to the genetic model which is proposed for development of colorectal cancer, the progressive acquisition of activity or loss of function is because of accumulation of sequential mutations in oncogenes and tumor suppressor genes such as adenomatous polyposis coli (APC), Kristen-ras (K-ras) and tumor suppressor protein 53, that drives healthy colonic epithelia through increasingly dysplasia adenoma to carcinoma transition [23].

TP53 is one of the most frequently mutated genes in human cancers and loss of TP53 function through mutation in a gene is the most important event in colorectal cancer development. The most common mutations are single base substitutions that alter protein function. Some of the mutations being oncogenic confer gain-of-function properties [24].

In the present study, we searched for mutations in the TP53 gene in colorectal cancer patients. Previously no such study has been conducted in Khyber Pakhtunkhwa nor in Pakistan. In this study, we extracted genomic DNA from 50 CRC patients and amplified exons 5, 7 and 8 of TP53 through PCR. We for the first time investigated and screened for mutation exons 5 , 7 and 8 from genomic DNA which were extracted from the blood of CRC patients by polymerase chain reaction (PCR). The PCR products were then purified and sequenced directly and obtained nucleotides sequences were compared with TP53 database sequence NC-191170 using CLUSTALW [25]. In our study we screened 50- CRC patients for a mutation in TP53 exons 5, 7 and 8 using PCR direct sequencing. Tp53 status and mutations were then correlated with the survival rates of CRC patients. In patient number 7 (T7) a point mutation was found at bp150 leading to GCT $\rightarrow$ ACT transition resulting in Threonine instead of Alanine. Similarly, in patient number 20 (T20) a point mutation was found at bp160 leading to ACC $\rightarrow$ ATC transition resulting in Isoleucine instead of Threonine. Another mutation was found in patient 5 exon 7 at bp 130 leading to GCA $\rightarrow$ ACA, resulting in Threonine instead of Alanine. No mutation was found in exon 8 in any other patient. Based on mutational data from 9000 colorectal tumors the most frequent mutations observed in both adenocarcinomas and carcinomas have been at codons 175 and 273. However, the observed frequency of mutation at codon 248 has been reported approximately three times higher in adenocarcinomas than in adenomas [26]. Many studies have reported the association of somatic mutations in TP53 or abnormal protein expression with poor survival or lack of response to therapy. However, the clinical significance of TP53 status still remains controversial [27]. We also found those patients have point mutations in their TP53 gene shows low prognosis as compared to that of those colorectal cancer patients having with TP53 gene.

Most of the studies on the clinical relevance of TP53 polymorphisms mainly focused on the role of Arg72Pro. The Arg72 variant has been reported to be a more potent inhibitor of chemotherapy-induced apoptosis than the corresponding Pro72 variant [28]. Thus, TP53 genotyping may be useful for stratification and selection of patients that will most benefit from certain molecularly targeted therapies.

\section{Conclusion}

Extraction and amplification of DNA even with old ages can be analyzed. The mutation is a sudden change in a gene. A point mutation was mostly found in exon 5 and 7 of the TP53 gene. Patients having TP53 gene mutations shown less survival rate compared to $\mathrm{CRC}$ patients having no mutations. Most of the work is needed in the future.

List of abbreviation

PCR: Polymerase chain reaction

CRC: Colorectal Cancer

EDTA: Ethylenediaminetetraacetic acid

P. R. China: People republic of China

IRNUM: Institute of Radiotherapy and nuclear medicine LRH: Lady Reading Hospital

KTH: Khyber Teaching Hospital

HMC: Hayatabad Medical Complex

NWGHP: North West General Hospital of Peshawar

\section{Declaration \\ Ethics consent to participate}

All procedures performed in studies involving human participants were following the ethical standards and the study was approved by the institutional committee of Department of Zoology, Kohat University of Science and Technology, Kohat 26000, Khyber Pakhtunkhwa, Pakistan according to 1964 Helsinki declaration. The participant voluntarily participates in the present study. The overall data was conducted in the form of questionnaire. 
Disclosures: There is no conflict of interest for all authors.

Funding: None.

Acknowledgment: Authors are also very grateful to "Department of Zoology, Kohat University of Science and Technology, Khyber Pakhtunkhwa, Pakistan" "School of Life Sciences, Lanzhou University, Lanzhou, Gansu, China” for providing a sound environment for laboratory work.

Author contribution: Contributions to the conception IK; design of the work; MAK; analysis, ZA interpretation of data; IS; have drafted the work IA; Substantively revision MJ; Experimental AF.

\section{References}

1. Rehman G, Gul N, Khan GN, et al. Ethanolic extract of Allacanthos crab inhibits cancer cell proliferation, posses anti-inflammatory and antioxidant potentials. Gene Reports. 2020; 21:100907. https://doi.org/10.1016/j.genrep.2020.100907

2. Qadir M, Ghalia BA. Awareness survey about colorectal cancer in students of M. Phil Biotechnology at Bahauddin Zakariya University, Multan, Pakistan. Nov Appro Can Study. 2018; 1.

3. Nejad AL, Yaghoobi MM. Mutation analysis of TP53 tumor suppressor gene in colorectal cancer in patients from Iran (Kerman Province). Iran J Basic Med Sci. 2012; 15(1):683-90.

4. Moghimi-Dehkordi B, Safaee A. An overview of colorectal cancer survival rates and prognosis in Asia. World J Gastrointest Oncol. 2012; 4(4):71-5. https://doi.org/10.4251/wjgo.v4.i4.71

5. Gao Z-G, Yang Y, Han X-F, et al. ALDH3B2 Polymorphism Is Associated with Colorectal Cancer Susceptibility. J Oncol. 2020; 2020:5179635. https://doi.org/10.1155/2020/5179635

6. Olivier M, Hollstein M, Hainaut P. TP53 mutations in human cancers: origins, consequences, and clinical use. Cold Spring Harb Perspect Biol. 2010; 2(1):a001008. https://doi.org/10.1101/cshperspect.a001008

7. Duffy MJ, Synnott NC, Crown J. Mutant p53 as a target for cancer treatment. Eur J Cancer. 2017; 83:258-265. https://doi.org/https:// doi.org/10.1016/j.ejca.2017.06.023

8. Ryan KM, Phillips AC, Vousden KH. Regulation and function of the p53 tumor suppressor protein. Curr Opin Cell Biol. 2001; 13(3):332-337. https://doi.org/10.1016/s0955-0674(00)00216-7

9. Shen J, Vakifahmetoglu H, Stridh H, et al. PRIMA-1Met induces mitochondrial apoptosis through activation of caspase-2. Oncogene. 2016; 35(50):6446. https://doi.org/10.1038/onc.2016.210

10. Haggar FA, Boushey RP. Colorectal cancer epidemiology: incidence, mortality, survival, and risk factors. Clin Colon Rectal Surg. 2009; 22(4):191-7. https://doi.org/10.1055/s-0029-1242458

11. Hasan F, Shah SMM, Munaf M, et al. Barriers to colorectal cancer screening in Pakistan. Cureus. 2017; 9(7):e1477. https://doi. org/10.7759/cureus. 1477

12. Siegel RL, Miller KD, Jemal A. Cancer statistics, 2015. CA Cancer j Clin. 2015; 65(1):5-29. https://doi.org/10.3322/caac.21254

13. Anwar N, Badar F, Yusuf MA. Profile of patients with colorectal cancer at a tertiary care cancer hospital in Pakistan. Ann N Y Acad Sci. 2008; 1138:199-203. https://doi.org/10.1196/annals.1414.026

14. Bhurgri Y, Khan T, Kayani N, et al. Incidence and current trends of colorectal malignancies in an unscreened, low risk population. Asian Pacific J Cancer Prev. 2011; 12(3):703-708

15. Ghorbani F, Kokhaei P, Ghorbani M, Eslami M. Application of different nanoparticles in the diagnosis of colorectal cancer. Gene Reports. 2020; 21:100896. https://doi.org/https://doi.org/10.1016/j.genrep.2020.100896

16. Zhang X, Wang W, Wang Y, et al. Human papillomavirus infection and colorectal cancer in the Chinese population: a meta-analysis. Color Dis. 2018; 20(11):961-969. doi: 10.1111/codi.14416.

17. Osumi H, Shinozaki E, Yamaguchi K, Zembutsu H. Early change in circulating tumor DNA as a potential predictor of response to chemotherapy in patients with metastatic colorectal cancer. Sci Rep. 2019; 9(1):17358. doi: 10.1038/s41598-019-53711-3.

18. Sharma A, Alatise OI, Adisa AO, et al. Treatment of colorectal cancer in Sub-Saharan Africa: Results from a prospective Nigerian hospital registry. J Surg Oncol. 2020; 121:342-349. https://doi.org/10.1002/jso.25768

19. Kakakhel MA, Wu F, Gu J-D, et al. Controlling biodeterioration of cultural heritage objects with biocides: A review. Int Biodeterior Biodegradation. 2019; 143:104721. https://doi.org/10.1016/j.ibiod.2019.104721

20. Brigger I, Dubernet C, Couvreur P. Nanoparticles in cancer therapy and diagnosis. Adv Drug Deliv Rev. 2002; 54(5):631-51. doi: 10.1016/s0169-409x(02)00044-3.

21. Warwick PD. Overview of the geography, geology and structure of the Potwar regional framework assessment project study area, northern Pakistan. Reg Stud Potwar Plateau Area, North Pakistan US Geol Surv Bull. 2007; 2078.

22. Frebourg T, Friend S. Cancer risks from germline p53 mutations. J Clin Invest. 1992; 90(5):1637-41. doi: 10.1172/JCI116034.

23. George B, Datar RH, Wu L, et al. p53 gene and protein status: the role of p53 alterations in predicting outcome in patients with bladder cancer. J Clin Oncol. 2007; 25(34):5352-8. doi: 10.1200/JCO.2006.10.4125.

24. Tominaga $\mathrm{T}$, Iwahashi M, Takifuji K, et al. Combination of $\mathrm{p} 53$ codon 72 polymorphism and inactive p53 mutation predicts chemosensitivity to 5-fluorouracil in colorectal cancer. Int J cancer. 2010; 126(7):1691-701. doi: 10.1002/ijc.24929.

25. Yu J, Wu WKK, Li X, et al. Novel recurrently mutated genes and a prognostic mutation signature in colorectal cancer. Gut. 2015; 64(4):636-45. doi: 10.1136/gutjnl-2013-306620.

26. Iacopetta B, Russo A, Bazan V, et al. Functional categories of TP53 mutation in colorectal cancer: results of an International Collaborative Study. Ann Oncol. 2006; 17(5):842-7. doi: 10.1093/annonc/mdl035.

27. Roth JA. p53 prognostication: Paradigm or paradox? Clin Cancer Res. 1999; 5(11):3345

28. Naccarati A, Polakova V, Pardini B, et al. Mutations and polymorphisms in TP53 gene - an overview on the role in colorectal cancer. Mutagenesis. 2012; 27(2):211-8. doi: 10.1093/mutage/ger067. 